\title{
Factors affecting the durability of GRC cement
}

\author{
Yue Yin ${ }^{1, a}$, ShengMi Wang ${ }^{2, b, \star}$, Maoquan Zhuang ${ }^{3, c}$, Mingzhe $\mathrm{Hu}^{1, \mathrm{~d}}$ \\ ${ }^{1}$ Physical and electronic science , Liupanshui Normal University , LiuPanShui 553004,china \\ ${ }^{2}$ Shenzhen Tengji Construction Engineering Co., Ltd, Shenzhen 518001, china \\ ${ }^{3}$ China 's first metallurgical construction limited liability company, Wuhan 430080, china

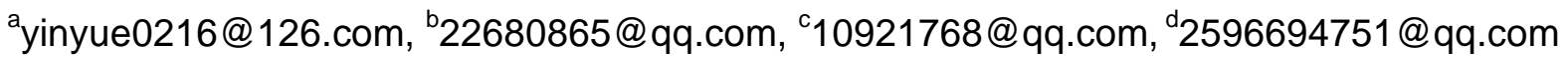 \\ * Corresponding author: e-mail: 22680865@qq.com
}

\section{Keywords: GRC, Endurance, Cement Matix}

Abstract.GRC is a concrete made of glass fiber, acting as reinforce matrix, and combined with cement. It has high tensile, bending and anti-impact properties. However, due to its endurance problem, it is prohibited in industry applications. In the recent thirty years, many researchers have investigated its endurance mechanism, and get that affect GRC durability is chemical erosion and physical erosion.

\section{Introduction}

GRC (Glassfiber Reinforced cement) is developed from the 40s of last century, which is a type of a composite building materials using cement mortar matrix and glass fiber reinforced body [1] [2] [2] 3] [4] . Glassfiber has high tensile strength (about 1770-2559MPa) and high elastic modulus (about 70GPa),which can improve the tensile strength and bending strength of cement matrix, also can improve the impact resistance of the matrix Strength and crack resistance. In addition, GRC material also has light weight, high plasticity, convenient processing, humidity and fire resistance and other

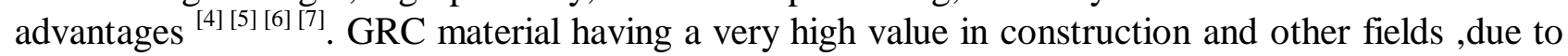
overcoming the shortcomings of traditional cement of poor tensile strength and impact resistance.

At present, GRC is more used in the field of non-load-bearing building components, along with its advantages of light and high strength, the long-term durability of GRC has become the main problem of limiting its wide range of applications. Since the middle of the last century, many researchers at home and abroad have been working on the long-term durability of GRC research, so that the durability of GRC has been effectively solved, and GRC has a wide range applications in many areas, such as construction, animal husbandry, fisheries and military engineering, etc. ${ }^{[4]}{ }^{[5][8]}{ }^{[9]}$. In this paper, the durability of GRC materials is reviewed and summarized from the perspectives of the mechanism of GRC durability reduction.

\section{GRC long-term performance degradation mechanism}

In order to solve the problem of poor long-term durability of GRC, many scholars at home and abroad have analyzed the mechanism of long-term performance degradation of GRC, and get that affect GRC durability is chemical erosion and physical erosion ${ }^{[10]}$. The chemical corrosion refers to that the tensile strength is reduced because glass fiber is corroded and damaged by irons in the alkaline cement slurry environment, which reduces the durability of glass fiber reinforced cement, and the long-term strength loss of the alkali-proof glass fiber concrete without the cladding is mainly caused by the chemical corrosion $^{[11]}$. The physical corrosion refers to that the cement hydration product especially $\mathrm{Ca}(\mathrm{HO})_{2}$ is filled in the gaps between glass fibers, and cemented with the glass monofilament, which easily results in local stress concentration on the fiber surface in case of matrix stress, thus to increase the brittleness of GRC materials ${ }^{[10]}$. The physical corrosion can be divided into two types-the microstructure change mechanism and the stress corrosion mechanism. The reasons for the long-term performance degradation of GRC are introduced from three aspects: chemical erosion mechanism, microstructure change mechanism and stress erosion mechanism. 
Chemical erosion mechanism. The chemical corrosion refers to that the tensile strength is reduced because glass fiber is corroded and damaged by irons in the alkaline cement slurry environment, which reduces the durability of glass fiber reinforced cement ${ }^{[11]}$. J.Olowsky et al. considered that the chemical corrosion was mainly divided into two stages: First, because the hydroxyl ions in the matrix are corroded, producing the hydration product, a protective layer is built on both fiber surfaces with the zirconia inside the fiber; second, after the protective layer is built, the corrosion speed is reduced, which can be almost neglected ${ }^{[12]}$.

In 1958, Jungan Xue et al. ${ }^{[13]}$ put forward in the study on the glass fiber corroded by the cement that $\mathrm{Ca}(\mathrm{OH})_{2}$ produced by the cement hydration may chemically react with the glass fiber, to produce the new gelatinous hydrated calcium silicate substance. In addition, such reaction is irreversible, which reacts rapidly until the reactants participate in the reaction completely. During the reaction process, the fiber surface has large defect due to the erosion of $\mathrm{Ca}(\mathrm{OH})$ 2, becoming the focal point of the stress, thus to greatly reduce the fiber strength and increase the brittleness.

After that, the foreign scholar L.Prodhomme ${ }^{[13]}$ put forward his own interpretation to the reaction mechanism for the chemical corrosion on the glass fiber during the cement hydration. He points out that when the glass fiber is in the water, the sodium silicate in the fiber may hydrolyze with the potassium silicate to produce hydrated silica ions and silicate gel, while potassium and sodium cations may further dissolve the silicon oxygen tetrahedron, which results in the acceleration of this hydrolysis process. The silicon oxygen tetrahedron may make the surface of the glass fiber have the relatively strong electronegativity, which absorbs the calcium ions in the solution and reacting with the above hydrated silica, to make the glass fiber in the water chemically corroded, and lose its original performance.

In addition, Litherland et al. ${ }^{[14]}$ put forward the similar opinion, believing that the reason why the glass fiber was chemically corroded in the cement matrix is that the $\mathrm{Ca}(\mathrm{OH})_{2}$ produced by the cement hydration chemically reacted with the glass fiber.

S. M. Budd ${ }^{[13]}$ believed that the glass fiber composed of the silicate was unstable in the alkaline medium, and the alkaline solution may chemically corrode the glass fiber, including the dissolution of sodium and calcium ions, and the "nucleophilic corrosion" of hydroxyl to the silicon-oxygen bond.

Zonghan Lou ${ }^{[15]}$ finds that the high alkalinity environment produced by the cement hydration may chemically corrode the glass fiber, thus to result in the loss of its tensile strength.

In 2012, Yamei Zang ${ }^{[16]}$ et al. carry out the accelerated aging test for the glass fiber reinforced magnesium oxychloride cement materials with SIC (Strand In Cement) test method, by which they believe that the strength loss for the glass fiber reinforced magnesium oxychloride cement board by SIC accelerated aging test should included the strength loss of middle alkali glass fiber chemically corroded in the magnesium oxychloride cement and the strength loss of the magnesium oxychloride cement in the flooded condition.

In 2016, Liming Liu ${ }^{[17]}$ et al. carried out the determination of rupture strength, compressive strength test and matrix $\mathrm{pH}$ value of glass fiber reinforced cement (GRC) specimen at different ages and different ambient humidity, and the determination results show that the ambient humidity has the significant impact on the rupture strength of GRC specimen. As ages increase, if the relative humidity is larger, the decrease in the rupture strength of GRC specimen is more serious.

Microstructure change mechanism. In 1969, Урьеь ${ }^{[18]}$ put forward the concept of the crystallization pressure, believing that the crystallization pressure produced by the crystal growth of cement hydrate in glass fiber micro-cracks and defects is one of the most important reasons for the reduction of glass fiber strength.

In 1975, Stucke, Majumdra ${ }^{[19]}$ put forward that the glass fiber may be physically corroded by the cement hydrate besides the chemical corrosion of $\mathrm{Ca}(\mathrm{OH})_{2}$ mentioned above. The hydration product may grow between internal fibers of the glass fiber, increasing the bond strength, thus to reduce the fiber flexibility. That is to say, the crystal growth of the cement hydrate may damage the glass fiber.

By experiment ,R.Hempel et al. get that the constant high alkalinity, temperature and humidity may cause rapid decomposition of fiber coating, thus, flaws of the main fiber are exposed, and the increased 
external stress early result in the damage to the fiber. At the same time, the coating layer of hydration product becomes thick as the exposure time increases, thus to reduce the ductility of the monofilament. Under the relatively low stress state, the relatively brittle coating layer is peeled off, and the monofilament is exposed, after which the large strain is produced, thus resulting in the damage of the fiber $^{[11]}$.

Stress corrosion mechanism. In 1975, Вирюкович ${ }^{[20]}$ put forward the stress corrosion theory, believing that the existence of glass fiber surface defects may cause the stress concentration of water, steam and cement hydrate at the defect ends, making the defect expand, thus to make the glass fiber damaged by the stress corrosion.

In 1978, Rongxi Shen ${ }^{[21]}$ put forward the damage of cement hydration product to chemical corrosion and stress corrosion of the glass fiber. He points out that the chemical corrosion results in the damage to silica skeleton, and the latter causes the expansion of the fiber surface defect. The interaction between both may greatly reduce the tensile strength of the glass fiber, and even completely disable it.

Pumell ${ }^{[22]}$ et al. find in the study on GRC of alkali resistant glass fiber Cem-Fil2 and OPC mixed with metakaolin or calcium sulphoaluminate that microstructure change mechanism and chemical corrosion are not obvious. The reduction of the durability is due to the stress corrosion mechanism.

Combined with the research progress at present, any one mechanism above cannot separately interpret the decrease in flexural strength and tensile strength of GRC materials in humid environment for a long term. For example, the mechanism for the chemical corrosion cannot well interpret the problem that the durability of the low alkalinity cement still decreases, because $\mathrm{Ca}(\mathrm{OH})_{2}$ is seldom produced therein; while the physical corrosion such as crystallization and stress cannot separately interpret the decrease in the durability of GRC in humid environment for a long term. Thus, the opinion generally accepted by the academic circle at present is that chemical corrosion interacts with the physical corrosion mechanism, thus to cause the corrosion mechanism for the decrease in the long-term durability of the glass fiber reinforced cement.

\section{Conclusions}

In this paper, the studies on the durability of GRC materials for 30 recent years are reviewed and summarized. After researches for nearly half a century, the factors influencing the durability of GRC summarized by foreign scholars mainly include: (1) the chemical corrosion mechanism for $\mathrm{Ca}(\mathrm{OH})_{2}$ in the cement matrix to the glass fiber; (2) the microstructure change mechanism for crystallization and growth of the cement hydration product $\mathrm{Ca}(\mathrm{OH})_{2}$ to the physical corrosion of the glass fiber; and (3) the stress corrosion mechanism caused by defects on the glass fiber surface and interface.

\section{Acknowledgements}

This work was financially supported by the Guizhou Provincial Science and Technology Department Technology Fund Project (QKHLHZ[2015]7633) and Guangdong Provincial Science and Technology Department commissioner workstation project (2011B090600021).

\section{References}

[1] Yuzhong Cui: Housing materials and applications.1998,4, p. 13-15, In Chinese.

[2] Qi Cui: Blocks and wall panels. 2004,10,p.23-26, In Chinese.

[3] Juhui Cao, Hongtao Wang : Architecture Technology. 2004,35(4),p.266-269, In Chinese.

[4] Zhicheng Liu, Qi Cui and Qinghai Li: Cement and concrete. 2015,p.41-44, In Chinese.

[5] Rongxi Shen : Silicate notification . 2005,5,p.55-59, In Chinese. 
[6] Yanmou Wang: China fiberglass reinforced cement[M]. China Building Materials Industry Press. 2000,3, In Chinese.

[7] Shaoqiu Huang, Zhexing Huang: Chinese building materials. 2001,8,p.60-61, In Chinese.

[8] Tianyou Bian: Glass fiber. 1998,5,p.17-20, In Chinese.

[9] Hongtao Wang, Juhui Cao, Ming Xue: Journal of Logistics Engineering University. 2009,3,25(2),p.1-4, In Chinese.

[10] Juhui Cao: Study on Durability of Glass Fiber Reinforced Ordinary Portland Cement[D]. Chongqing University. 2004, In Chinese.

[11] Nan Yang: Experimental Study on High Performance Concrete of Glass Fiber and Hybrid Fiber[D]. Dalian University of Technology. 2005, In Chinese.

[12] Jungan Xue, zhan Wang, Jiajun Yan: 1961 Cement Conference Proceedings. 1961, In Chinese.

[13] Yanling Cui: Study on the Durability of GRC and Its Mechanism[D]. China Building Materials Science Research academy.2007, In Chinese.

[14] Litherland K.L,Oakley DR,Proctor BA:Cement and Concrete Research.1981,11,p.455-466

[15] Zonghan Lou: Journal of the Chinese Ceramic Society. 1996,24,p.609-614, In Chinese.

[16] Yamei Zang, Lianxin Liu, Hongfa Yu et al.: New building materials. 2012,4,p.61-64, In Chinese.

[17] Liming Liu, Jize Mao, Jianfu Lu et al.: Journal of Composites. .2016,5. 33(5),p.1072-1078, In Chinese.

[18] Урьеь Н.В..Неорганические Материалы, 1975,45:249

[19] Stucke M.D,Majumdar A.J.: Mater Sci.1976,11,p.1019-1030

[20] К.Л.Вирюкович.Строителтьные Материалы,1975,6,p.33-44

[21] Rongxi Shen: Journal of the Chinese Ceramic Society. 1978,8,p.199-213, In Chinese.

[22] Purnell P.,Short N.R.,Page C.L,Majumdar A.J.: Cement and Concrete Research 2000, 30:p.1747-1753 